\title{
A Blocker of N-and T-type Voltage-Gated Calcium Channels Attenuates Ethanol-Induced Intoxication, Place Preference, Self-Administration, and Reinstatement
}

\author{
Philip M. Newton, ${ }^{1}$ Lily Zeng, ${ }^{1}$ Victoria Wang, ${ }^{1}$ Jacklyn Connolly, ${ }^{1}$ Melisa J. Wallace, ${ }^{1}$ Chanki Kim, ${ }^{2}$ Hee-Sup Shin, ${ }^{2}$ \\ Francesco Belardetti, ${ }^{3}$ Terrance P. Snutch, ${ }^{3,4}$ and Robert 0 . Messing ${ }^{1}$ \\ ${ }^{1}$ Ernest Gallo Clinic and Research Center, Department of Neurology, University of California, San Francisco, Emeryville, California 94608, ${ }^{2}$ Center for \\ Neural Science, Korea Institute of Science and Technology, 136-791 Seoul, Republic of Korea, ${ }^{3}$ Neuromed Pharmaceuticals, Vancouver, British Columbia, \\ Canada V6T 1Z3, and ${ }^{4}$ Michael Smith Laboratories, University of British Columbia, British Columbia, Canada V6T 1 Z4
}

There is a clear need for new therapeutics to treat alcoholism. Here, we test our hypothesis that selective inhibitors of neuronal calcium channels will reduce ethanol consumption and intoxication, based on our previous studies using knock-out mice and cell culture systems. We demonstrate that pretreatment with the novel mixed N-type and T-type calcium channel antagonist 1-(6,6-bis(4fluorophenyl)hexyl)-4-(3,4,5-trimethoxybenzyl)piperazine (NP078585) reduced ethanol intoxication. NP078585 also attenuated the reinforcing and rewarding properties of ethanol, measured by operant self-administration and the expression of an ethanol conditioned place preference, and abolished stress-induced reinstatement of ethanol seeking. NP078585 did not affect alcohol responses in mice lacking $\mathrm{N}$-type calcium channels. These results suggest that selective calcium channel inhibitors may be useful in reducing acute ethanol intoxication and alcohol consumption by human alcoholics.

Key words: alcoholism; calcium channel; $\mathrm{N}$ type; $\mathrm{T}$ type; conotoxin; addiction; relapse.

\section{Introduction}

Alcohol abuse and alcoholism are significant public health issues. In the United States, alcohol use disorders affect $\sim 14$ million people, costing approximately $\$ 184$ billion per year because of legal costs, lost wages, and medical costs (Kenna et al., 2004a,b). To date, only three drugs have been approved for treatment in the United States: disulfuram, naltrexone, and acamprosate. Use of these drugs is constrained by their limited efficacy, side effects and low patient compliance (Kenna et al., 2004b). It is estimated that $40-70 \%$ of patients return to excessive drinking within a year of treatment (Finney et al., 1996).

Given the current therapeutic limitations, there is a need to develop new treatments for alcoholism. One approach is to identify targets of ethanol action and then determine whether modulation of these targets can favorably alter behavioral responses to alcohol. The function of voltage-gated calcium channels is altered at ethanol concentrations that affect humans (Walter and Mess-

\footnotetext{
Received July 31, 2008; revised Sept. 18, 2008; accepted Sept. 20, 2008.

This work was supported by United States Public Health Service Grants AA008117 and AA013588 (R.0.M.) and funds provided by the State of California for medical research on alcohol and substance abuse through the University of California at San Francisco. T.P.S. is supported by Canadian Institutes of Health Research Operating Grant 10677 and is a Tier 1 Canada Research Chair in Biotechnology and Genomics-Neurobiology. H.S.S. is supported by a National Honor Scientist grant from the Ministry of Science and Technology, Republic of Korea, and a Center-of-Excellence grant from the Korea Institute of Science and Technology.

T.P.S and F.B. have received stock options from Neuromed Pharmaceuticals.

Correspondence should be addressed to Dr. Robert 0. Messing, Ernest Gallo Clinic and Research Center, 5858 Horton Street, Suite 200, Emeryville, CA 94608. E-mail: romes@gallo.ucsf.edu.

DOI:10.1523/JNEUROSCI.3621-08.2008

Copyright $\odot 2008$ Society for Neuroscience $\quad 0270-6474 / 08 / 2811712-08 \$ 15.00 / 0$
}

ing, 1999). These channels mediate $\mathrm{Ca}^{2+}$ entry into neurons in response to changes in membrane potential, regulating neuronal excitability, neurotransmitter release, and gene expression (Dunlap et al., 1995; Ghosh and Greenberg, 1995). They have been classified as L-, N-, P/Q-, R-, and T-types according to their distinct electrophysiological and pharmacological properties (Dunlap et al., 1995).

High voltage-activated N-type calcium channels are exclusively expressed in the nervous system where they contribute to neurotransmitter release at a subset of central and peripheral nerve terminals (Dubel et al., 1992; Snutch, 2005). We have shown previously that acute ethanol exposure inhibits $\mathrm{N}$-type calcium channels (Solem et al., 1997), and chronic ethanol exposure increases $\mathrm{N}$-type channel function and density (McMahon et al., 2000; Newton et al., 2005). Low voltage-activated T-type calcium channels are biophysically distinct from $\mathrm{N}$-type channels and contribute to rhythmic firing and bursting behaviors related to processes such as sleep and epileptiform activity (Huguenard, 1996). Ethanol appears to have complex effects on T-type currents. In slices from the lateral geniculate nucleus, low concentrations $(\leq 10 \mathrm{~mm})$ of ethanol potentiate T-type currents, whereas higher ethanol concentrations ( $\geq 20 \mathrm{~mm}$ ) inhibit T-type currents (Mu et al., 2003).

Mice lacking N-type calcium channels show reduced sensitivity to the hypnotic effect of ethanol and decreased voluntary ethanol consumption (Newton et al., 2004). This phenotype suggested that pharmacological inhibition of N-type calcium channels may be an effective strategy to reduce ethanol intoxica- 
tion and consumption. Here we tested this hypothesis pharmacologically using a novel mixed inhibitor of N-type and T-type calcium channels, 1-(6,6-bis(4-fluorophenyl)hexyl)-4-(3,4,5trimethoxybenzyl)piperazine (NP078585) (Snutch et al., 2001, 2003; Xiao et al., 2008). NP078585 is the first generation compound of a novel pharmacological class of orally bioavailable N-type calcium channel inhibitors, some of which are in clinical trials for the treatment of chronic pain (The Healthcare Marketing and Sales Network, March 20, 2006). Because alcoholism is a heterogenous disease with many different facets, we assessed the effects of NP078585 in multiple animal paradigms that model ethanol intoxication, reinforcement, reward, and reinstatement (Egli, 2005).

\section{Materials and Methods}

Drugs. NP078585 (1-(6,6-bis(4-fluorophenyl)hexyl)-4-(3,4,5-trimethoxybenzyl)piperazine (supplied by Neuromed Pharmaceuticals) was dissolved in polyethylene-glycol 400 vehicle (Fisher) by vortexing and brief $(\sim 5 \mathrm{~min})$ sonication. All injections were given intraperitoneally. NP078585 inhibits N-type calcium channels in vitro with a $K_{\mathrm{d}}$ of $\sim 110$ nм. NP078585 also inhibits rat brain T-type calcium channels containing $\mathrm{Ca}_{\mathrm{V}} 3.1$ subunits with a $K_{\mathrm{d}}$ of $\sim 200 \mathrm{nM}$, those containing $\mathrm{Ca}_{\mathrm{V}} 3.2$ subunits with a $K_{\mathrm{d}}$ of $\sim 520 \mathrm{~nm}$ and those containing $\mathrm{Ca}_{\mathrm{V}} 3.3$ subunits with a $K_{\mathrm{d}}$ of $\sim 250 \mathrm{~nm} . K_{\mathrm{d}}$ values for the inhibition of P/Q channels containing $\mathrm{Ca}_{\mathrm{v}} 2.1$ and L-type calcium channels containing $\mathrm{Ca}_{\mathrm{v}} 1.2$ are 1450 and 2810 nM respectively. Intraperitoneal injection of rats or mice with NP078585 dissolved in polyethylene-glycol 400 results in brain concentrations sufficient to inhibit $\mathrm{N}$-type calcium channels within $30 \mathrm{~min}\left(\mathrm{C}_{\max } \sim 450\right.$ $\mathrm{nm}$ ). Within $24 \mathrm{~h}$, the concentration drops to $22.5 \mathrm{~nm}$ (rats) or below detectable levels (mice). The full characterization and pharmacokinetics of NP078585 are being published separately.

Animals. Wild-type and $C a_{V} 2.2(-/-)$ mice lacking the pore forming $\alpha 1$ subunit of $\mathrm{N}$-type calcium channels were maintained on an $\mathrm{F} 1$ hybrid C57BL/6J $\times 129 /$ S4 background (Newton et al., 2004). Wild-type mice on this background were used for loss of righting reflex (LORR), rotarod, and ethanol clearance studies. $\mathrm{Ca}_{V} 2.2(-/-)$ mice were also included in the LORR experiment. For place preference and locomotor studies, we used wild-type DBA/2 mice (Taconic), as this strain has been repeatedly shown to exhibit robust ethanol responses in both paradigms (Cunningham et al., 1998; Lessov et al., 2001). For operant self-administration and reinstatement studies we used Long-Evans rats (Harlan). Animal use was in accordance with institutional and National Institutes of Health guidelines. All experiments were performed with naive male mice or rats, except rotarod studies, in which animals were tested first on a fixed speed rotarod and then on an accelerating rotarod.

Locomotor activity in mice. Mice were individually habituated to openfield chambers (Med Associates) in three 20 min sessions on consecutive days. Each session was preceded by a saline injection. On the fourth day, mice were given NP078585 or vehicle and returned to their home cage for $30 \mathrm{~min}$. They were then injected with ethanol or saline and placed in the open field for $20 \mathrm{~min}$. The presence of locomotor stimulation was determined for each treatment group by comparing the distance traveled on the test day with distance traveled during the third habituation session by paired, two-tailed $t$ tests.

Rotarod. Mice were trained to remain on a fixed speed (12 rpm) rotarod for $180 \mathrm{~s}$ (Ugo Basile). The following day each mouse was tested to ensure it could stay on the rotarod for $180 \mathrm{~s}$, and then injected with either NP078585 or vehicle and retested 30 min later (time 0 ). Mice were then injected with ethanol and retested every $15 \mathrm{~min}$ for $1 \mathrm{~h}$. Mice received 1.5 $\mathrm{g} / \mathrm{kg}$ ethanol in the first test session (experiment 1 ) and $2 \mathrm{~g} / \mathrm{kg}$ ethanol $10 \mathrm{~d}$ later (experiment 2). After an additional $25 \mathrm{~d}$, they were tested on an accelerating rotarod (3-30 rpm over $300 \mathrm{~s}$ ) after injection of $2 \mathrm{~g} / \mathrm{kg}$ ethanol (experiment 3). Mice that received NP078585 in experiment 1 received vehicle in experiment 2 and then NP078585 again in experiment 3 , resulting in a $35 \mathrm{~d}$ gap between repeat administration of NP078585.

Loss of the righting reflex. Mice were pretreated with vehicle or NP078585 $30 \mathrm{~min}$ before ethanol $(4.0 \mathrm{~g} / \mathrm{kg})$. Loss of the righting reflex was defined as a mouse being unable to right itself three times within $30 \mathrm{~s}$ after ethanol injection. After losing the righting reflex, mice were placed on their backs and the time taken for them to regain the righting reflex (i.e., being able to right themselves three times in $30 \mathrm{~s}$ ) was measured.

Place conditioning. DBA/2 mice were trained in open-field chambers (ENV-515, Med Associates) equipped with two-chamber place preference inserts (ENV-517, Med Associates). One chamber consisted of a mesh floor with white walls while the other chamber had a rod floor with black walls. Chambers were separated by a manual guillotine door that was closed during training and open during habituation and test sessions. Before training, animals were habituated to the apparatus by allowing them $30 \mathrm{~min}$ free access to both chambers. DBA/2 mice used in these experiments did not display a baseline preference for either chamber (data not shown). Thus, equal numbers of animals received the unconditioned stimuli in either chamber. To assess the effect of NP078585 on the expression of an ethanol conditioned place preference (CPP), mice were trained in a standard ethanol CPP paradigm (Newton et al., 2004; Newton and Messing, 2007) consisting of eight 5 min conditioning sessions, four with saline and four with ethanol $(2 \mathrm{~g} / \mathrm{kg}$, i.p.). One conditioning session was given per day and sessions were alternated (saline $1 \mathrm{~d}$, ethanol the next). On the day after the final conditioning session, mice were tested for CPP by allowing them $30 \mathrm{~min}$ access to both chambers. NP078585 $(25 \mathrm{mg} / \mathrm{kg})$ or vehicle was given $30 \mathrm{~min}$ before the test and mice remained in their home cage for those $30 \mathrm{~min}$. Time spent in the ethanol-paired side was compared with time spent in the saline-paired side using a Wilcoxon signed rank test (Newton et al., 2004; Newton and Messing, 2007; Newton et al., 2007). To assess the effect of NP078585 on the expression of a $\mathrm{LiCl}$ conditioned place aversion we used the same protocol except that conditioning trials were $30 \mathrm{~min}$ and the test was 60 $\mathrm{min}$. $\mathrm{LiCl}(3 \mathrm{mEq} / \mathrm{kg}$, i.p.) was given in place of ethanol (Risinger and Cunningham, 2000).

Operant ethanol self-administration. Long-Evans rats were trained to lever press for ethanol in operant chambers (Med-Associates) according to established methods with a 26 day sucrose fade in the home cage (Burattini et al., 2006). Rats were then water deprived overnight and trained to lever press in the operant chambers in an overnight session with 2 active levers delivering 10\% ethanol on an FR1 schedule. After the overnight session they were given water in the home cage for $8 \mathrm{~h}$. They were again water deprived overnight and the following day placed in the operant chambers for $45 \mathrm{~min}$ with only one (right) lever delivering 10\% ethanol on an FR1 schedule. The left lever was presented but was inactive and pressing it did not result in any programmed consequence. They were then allowed access to water for $1 \mathrm{~h}$ in the home cage. These $45 \mathrm{~min}$ sessions after overnight water deprivation were continued for $3 \mathrm{~d}$, after which ad libitum water access in the home cage was restored. FR1 sessions were continued $5 \mathrm{~d}$ /week (Monday through Friday) for 4 weeks. Baseline responding was then established in $30 \mathrm{~min}$ sessions on an fixed-ratio 3 (FR3) schedule for 4 weeks (weeks 1-4, 20 sessions). Rats that failed to demonstrate a mean daily ethanol intake of at least $0.3 \mathrm{~g} / \mathrm{kg} / \mathrm{session}$ by week 4 were eliminated from the study. During the fifth week, animals were habituated twice to vehicle injections in sessions $2 \mathrm{~d}$ apart. Injections were given in the home cage $30 \mathrm{~min}$ before entry into the operant chambers. Remaining sessions that week were as in the previous 4 weeks. During weeks 6-11, animals were given one injection per week of either

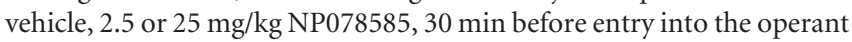
chambers. Drug treatment was in a random order, and each animal received all concentrations twice, once a week on Thursdays. Data for individual animals were averaged at each concentration of NP078585. Throughout the baseline and test sections of the experiment, chambers and reward ports were examined after every session for the presence of unconsumed alcohol. None was observed.

Stress-induced reinstatement of operant ethanol self-administration. A separate group of Long-Evans rats were trained in the operant paradigm described above, including habituation to vehicle injection. Operant behavior was then extinguished during 6 weeks during which lever pressing did not result in the delivery of ethanol but did activate the syringe pump. After 6 weeks, responses on the active lever had reached $<10 \%$ of those during the final week of ethanol delivery. Animals were divided into two groups matched for responses during the final week of ethanol delivery and the final week of extinction. Half the animals were injected with vehicle and half were injected with $25 \mathrm{mg} / \mathrm{kg}$ NP078585. Only one injec- 
tion of either vehicle or NP078585 was given. Thirty minutes later, all animals were injected with $2.5 \mathrm{mg} / \mathrm{kg}$ yohimbine in water. After an additional $30 \mathrm{~min}$ the animals were placed in the chambers for a $30 \mathrm{~min}$ operant session using conditions identical to those used during extinction (Lê et al., 2005).

Locomotor activity in rats. To control for effects of NP078585 on the general locomotor activity of Long-Evans rats, we used Med Associates rat locomotor activity boxes (ENV-515). Rats were habituated to the chambers over 4 daily 30 min sessions. On the fifth day, animals were treated with the same combinations of vehicle, NP078585 $(25 \mathrm{mg} / \mathrm{kg}$, i.p.) and yohimbine $(2.5 \mathrm{mg} / \mathrm{kg}$, i.p. $)$ used in the operant selfadministration experiments.

Ethanol clearance. F1 hybrid C57BL/6J $\times 129 / \mathrm{S} 4$ mice $(n=8$ per group) were pretreated with vehicle (PEG-400) or NP078585 (25 mg/kg, i.p.), $30 \mathrm{~min}$ before $4 \mathrm{~g} / \mathrm{kg}$ ethanol. Blood samples were then taken from the tail 30, 90, and 180 min later. Serum alcohol concentrations were determined using an Analox AM-1 analyzer (Analox Instruments).

Statistical analyses. All data are expressed as mean \pm SEM values. Means were compared by two-tailed $t$ tests or by ANOVA with post hoc Bonferroni's tests except, as noted above, for CPP studies where means were compared by Wilcoxon signed rank tests.

\section{Results}

\section{NP078585 attenuates the acute effects of ethanol}

We examined the effect of NP078585 on ethanol-stimulated locomotor activity (Fig. $1 \mathrm{~A})$. Ethanol $(2 \mathrm{~g} / \mathrm{kg})$ caused a significant stimulation in vehicle pretreated animals $(p<0.001)$. This stimulation was abolished by pretreatment with $25 \mathrm{mg} / \mathrm{kg}$ NP078585 $(p=0.5674)$ but not $2.5 \mathrm{mg} / \mathrm{kg}$ NP078585 ( $p<0.001)$. Treatment with NP078585 alone had no significant effect on locomotor activity $(p=0.244)$.

We next examined whether NP078585 would decrease ethanol-induced ataxia. On a fixed-speed rotarod NP078585 did not affect ethanol-induced ataxia (data not shown). On the accelerating rotarod, animals pretreated with $25 \mathrm{mg} / \mathrm{kg}$ NP078585 showed significantly reduced ataxia. A two-way ANOVA with a between-subjects factor for treatment (NP078585 or vehicle) and a within-subjects factor for time showed main effects of treatment $\left(F_{(1,92)}=19.08 ; p<0.001\right)$ and time $\left(F_{(6,92)}=77.040 ; p<\right.$ $0.001)$ with an interaction between these two factors $\left(F_{(6,92)}=\right.$ 4.483; $p<0.001)$. Post hoc Bonferroni tests showed a significant difference between vehicle and NP078585 treated animals at all times except time 0 , demonstrating that NP078585 alone did not cause ataxia (Fig. $1 B$ ).

To confirm that NP078585 was at least partially acting through $\mathrm{N}$-type calcium channels, we assessed the effect of NP078585 on ethanol-induced ( $4 \mathrm{~g} / \mathrm{kg}$, i.p.) LORR in mice lacking N-type calcium channels. Confirming previous work (Newton et al., 2004), these mice showed a reduced LORR duration compared with wild-type animals and their LORR duration was unaffected by pretreatment with NP078585. In contrast, the LORR duration of wild-type animals was substantially attenuated by pretreatment with NP078585 (Fig. 1C). A two-way ANOVA showed main effects of both genotype $\left(F_{(1,24)}=40.17 ; p<\right.$ $0.0001)$ and treatment $\left(F_{(1,24)}=27.69 ; p<0.0001\right)$ and an interaction between these factors $\left(F_{(1,24)}=14.43 ; p=0.007\right)$. Post hoc Bonferroni tests revealed a specific effect of NP078585 in wildtype animals only $(p<0.001)$.

\section{NP078585 reduces ethanol reward and reinforcement}

To investigate the effect of NP078585 on ethanol's conditioned motivational properties we examined ethanol-induced CPP in mice. DBA/2 mice were trained in a standard ethanol CPP paradigm consisting of four ethanol and four saline treatments on intervening days (Newton et al., 2004; Newton and Messing,
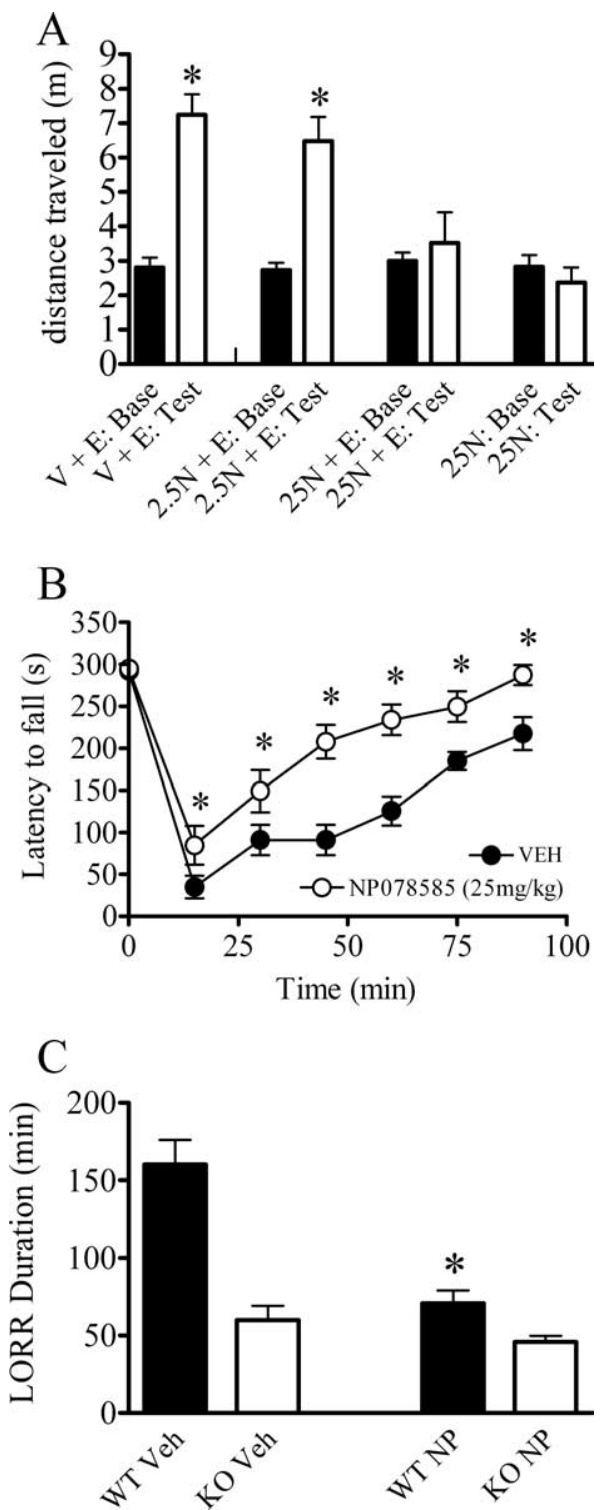

Figure 1. NP078585 reduces acute motor effects of ethanol in mice. $\boldsymbol{A}$, Pretreatment with 25 $\mathrm{mg} / \mathrm{kg} \mathrm{NP078585}$ abolished the locomotor-stimulating effects of ethanol. Mice were injected with either NP078585 (N) or vehicle (V) 30 min before $2 \mathrm{~g} / \mathrm{kg}$ ethanol (E). Data was compared between test day (Test, when ethanol was given) and the previous day (Base). $\boldsymbol{B}$, Ethanol-induced ataxia was attenuated on the accelerating rotarod. C, Pretreatment with $25 \mathrm{mg} / \mathrm{kg}$ NP078585 (NP) reduced the duration of the ethanol $(4 \mathrm{~g} / \mathrm{kg}$ )-induced loss of the righting reflex in wild-type (WT) mice but not in mice lacking $\mathrm{N}$-type calcium channels (KO) $\left({ }^{*} p \leq 0.05 ; n=9-10\right.$ per group).

2007). On the test day (no ethanol or saline treatment) animals were given either vehicle or NP078585 $(25 \mathrm{mg} / \mathrm{kg}) 30 \mathrm{~min}$ before the preference test. Treatment with NP078585 abolished the expression of an ethanol CPP (Fig. 2A). Wilcoxon signed rank tests revealed significant preference for the ethanol-paired side only in animals pretreated with vehicle. Locomotor activity of mice in the test chambers was not affected by NP078585 during the test. Distance traveled $(\mathrm{cm})$ for vehicle-treated mice was $514.7 \pm$ 122.2 and for NP078585 treated mice was $423.4 \pm 120.1$ An unpaired $t$ test comparing locomotor activity in the two groups revealed no significant difference $(p=0.6)$. To determine whether NP078585 caused a general impairment of the recall of a conditioned stimulus we assessed the effect of NP078585 on the expression of a lithium chloride conditioned place aversion. $\mathrm{LiCl}$ produced a conditioned response similar in magnitude to that 

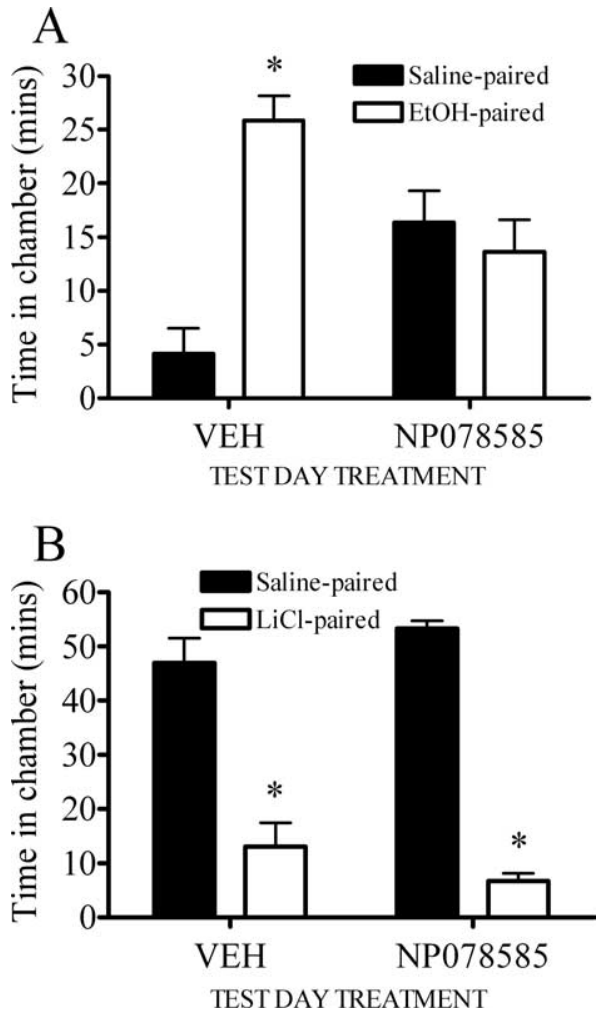

Figure 2. Expression of an ethanol conditioned place preference by DBA/2 mice is abolished by NP078585. A, NP078585 abolished the expression of ethanol conditioned place preference when given on the test day. $\boldsymbol{B}$, NP078585 did not affect the expression of a lithium chloride conditioned place aversion ( $n=12$ per group). ${ }^{*} p<0.05$ by Wilcoxon signed rank test.

obtained with ethanol. NP078585 did not affect the expression of this conditioned place aversion. Wilcoxon signed rank tests revealed a significant preference for the saline-paired side in animals pretreated with either vehicle or NP078585 (25 mg/kg) (Fig. 2B).

Next we examined ethanol reinforcement by assessing the effects of NP078585 on operant self-administration of ethanol. We used Long-Evans rats trained to self-administer $>0.3 \mathrm{~g} / \mathrm{kg}$ ethanol in daily 30 min sessions (Monday through Friday) on an FR3 schedule. Mean responding after training was for $0.473 \mathrm{~g} / \mathrm{kg}$ per session, which in the Long-Evans rats used here would be expected to result in a blood alcohol concentration of $20-25 \mathrm{mg} \%$, approximately the level achieved by human social drinkers (Czachowski et al., 1999; Gauvin, 1999; Roberts et al., 1999) Rats were given vehicle, 2.5 or $25 \mathrm{mg} / \mathrm{kg}$ NP078585 $30 \mathrm{~min}$ before the Thursday operant session. Data from Tuesday and Wednesday were averaged to calculate a baseline level of responding. NP078585 pretreatment had no effect on operant responding on the day it was given, but animals treated with $25 \mathrm{mg} / \mathrm{kg}$ NP078585 showed a significant reduction in responding the day after treatment (Friday) (Figs. $3 A, B$ ), and responding recovered to baseline levels by the following Monday ( $63.7 \pm 7.4$ at baseline vs $74.62 \pm$ 9.0 on Monday, $p=0.3$ by paired $t$ test). A two-way repeatedmeasures ANOVA for lever pressing with a repeated measure for time and a between-subjects factor for dose showed a main effect of dose $\left(F_{(2,40)}=4.275 ; p=0.028\right)$ and an interaction between treatment time and dose $\left(F_{(4,40)}=3.644 ; p=0.013\right)$. Post hoc Bonferroni tests revealed a significant difference between 25 $\mathrm{mg} / \mathrm{kg}$ and both vehicle $(p<0.001)$ and $2.5 \mathrm{mg} / \mathrm{kg}(p=0.047)$ NP078585 on the day after treatment, as well as a significant difference between baseline and "day after" responding for the 25
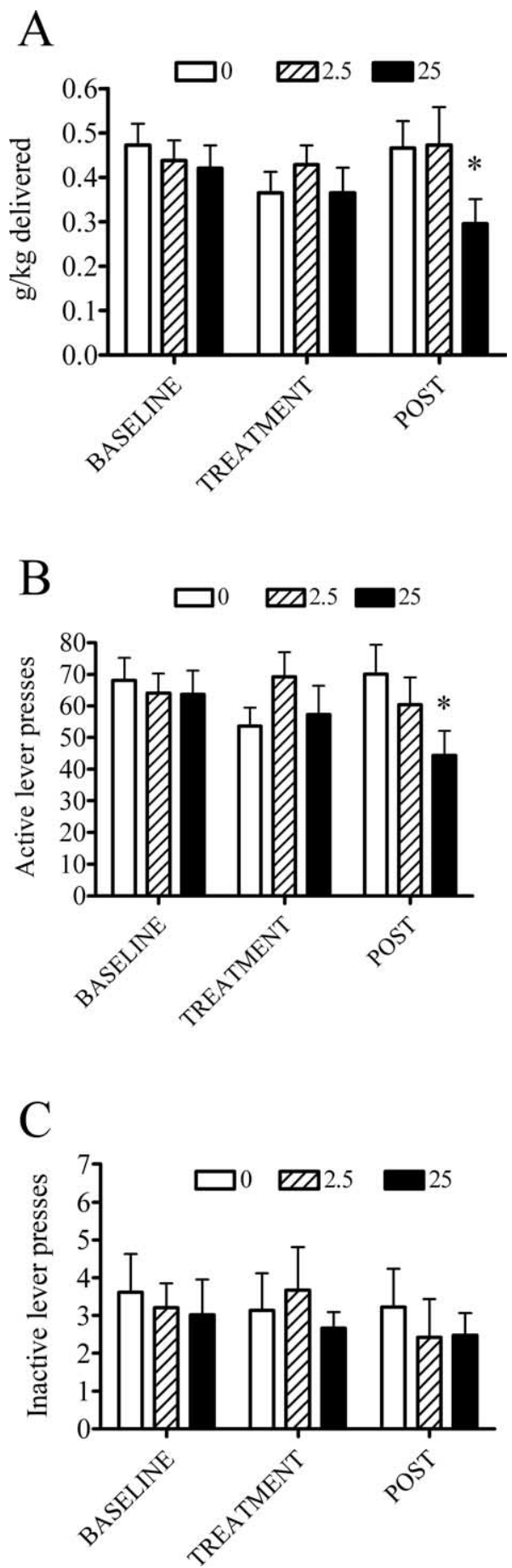

Figure 3. NP078585 has a delayed inhibitory effect on operant ethanol self-administration by Long-Evans rats. $\boldsymbol{A}, \boldsymbol{B}$, Data are presented as $(\boldsymbol{A})$ amount of ethanol delivered in $\mathrm{g} / \mathrm{kg}$ or $(\boldsymbol{B})$ active lever presses. NP078585 pretreatment had no effect on operant responding on the day it was given, but animals treated with $25 \mathrm{mg} / \mathrm{kg}$ NP078585 showed a significant reduction in responding the day after treatment. $C$, Responding on the inactive lever was not affected by NP078585 ( ${ }^{*} p<0.05, n=11$ per group)

$\mathrm{mg} / \mathrm{kg}$ treatment $(p=0.032)$. A two-way repeated-measures ANOVA for $\mathrm{g} / \mathrm{kg}$ self-administered with a repeated measure for time and a between-subjects factor for NP078585 dose showed a main effect of dose $\left(F_{(2,40)}=7.607, p=0.0058\right)$ but no significant effect of day and no interaction. However, comparing data within "day after" by one-way ANOVA showed a significant difference 

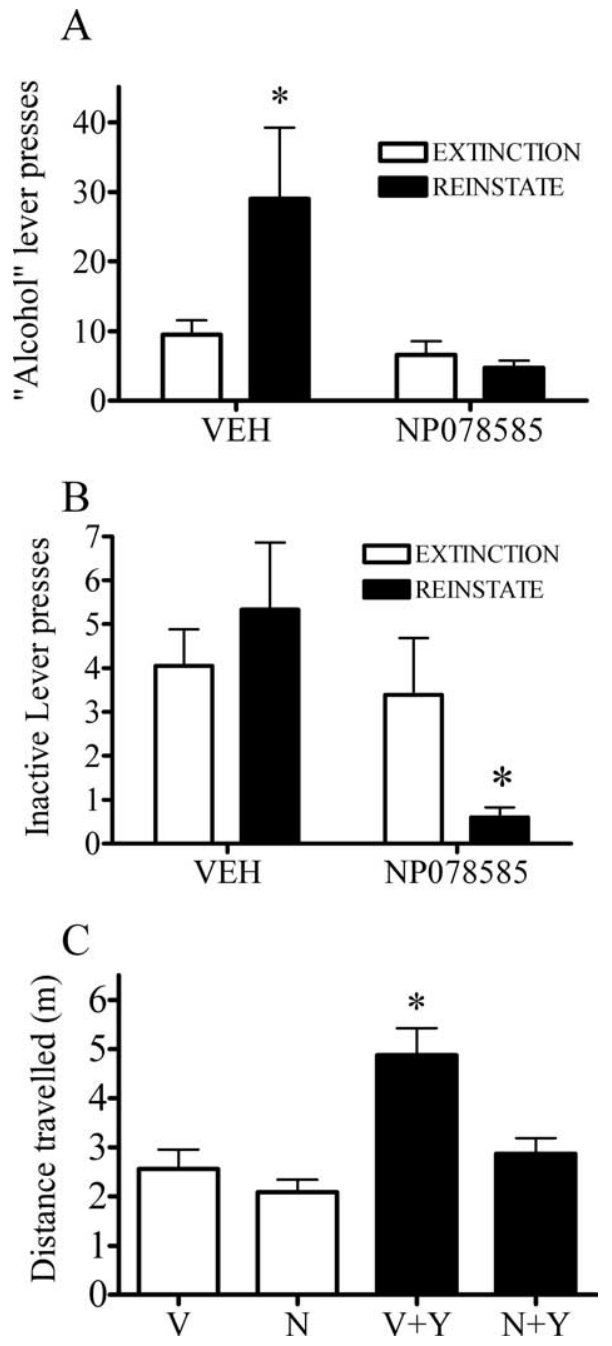

Figure 4. NP078585 prevents the reinstatement of operant ethanol seeking by the pharmacological stressor yohimbine. Long-Evans rats were trained to self-administer ethanol and then extinguished over a 6 week period (Extinction). Responding was then reinstated with the pharmacological stressor yohimbine (Reinstate). $\boldsymbol{A}$, Responding on the "alcohol" lever (which had previously been active before extinction) was significantly reinstated by yohimbine in PEG-400 pretreated animals (Veh), but this effect was abolished by pretreatment with $25 \mathrm{mg} / \mathrm{kg}$ NP078585. B, Yohimbine did not increase responding on the inactive lever, but the combination of yohimbine and NP078585 reduced responding on the inactive lever $\left({ }^{*} p<0.05 ; n=9-10\right.$ per group). C, NP078585 (N) did not alter locomotor activity relative to its vehicle (V). Yohimbine (Y) stimulated locomotor activity, an effect that was abolished by NP078585 $\left({ }^{*} p<0.05 ; n=\right.$ 12 per group).

between $25 \mathrm{mg} / \mathrm{kg}$ and both vehicle and $2.5 \mathrm{mg} / \mathrm{kg}$. Responding on the inactive levers (Fig. 3C) was not affected by NP078585.

\section{Stress-induced reinstatement to operant ethanol seeking}

We used yohimbine to assess the effects of NP078585 on stressinduced reinstatement to alcohol seeking. Yohimbine is an alpha2 adrenergic receptor antagonist that produces reinstatement of extinguished operant ethanol seeking via a CRF-1 receptordependent mechanism (Lê et al., 2005; Gass and Olive, 2007; Marinelli et al., 2007). Rats were pretreated with either vehicle or NP078585, 30 min before receiving yohimbine. Yohimbine produced a significant reinstatement of alcohol seeking in animals pretreated with vehicle, but not in rats pretreated with NP078585 (Fig. 4A). A two-way repeated-measures ANOVA with a between subjects factor for pretreatment drug (NP078585 or vehicle) and a repeated measure for behavioral state (extinction versus yohimbine-induced reinstatement) showed a significant main effect of pretreatment $\left(F_{(1,17)}=6.632 ; p=0.020\right)$ but not yohimbine $\left(F_{(1,17)}=3.345 ; p=0.085\right)$, although there was a significant interaction between the two factors $\left(F_{(1,17)}=4.916 ; p=0.041\right)$. Post hoc Bonferroni tests revealed a significant difference between yohimbine and vehicle treatment in animals pretreated with vehicle $(p=0.013)$ but not in animals pretreated with NP078585 $(p=0.781)$. Although these data did not show homogenous variances, the ANOVA is considered valid where sample sizes are equal, or almost equal (Zar, 1984; Dawson-Saunders and Trapp, 1994). Nevertheless we also conducted a nonparametric analysis to confirm our ANOVA results. There is no nonparametric equivalent of a two-way repeated-measures ANOVA, so we used the Wilcoxon signed-rank test as a nonparametric repeatedmeasures test to compare the effects of yohimbine-induced reinstatement in animals that had been treated with either vehicle or NP078585. For rats pretreated with vehicle, the effect of yohimbine was significant when compared with responding under extinction conditions ( $p=0.05$ ), whereas for those rats treated with NP078585 yohimbine had no effect ( $p=0.492)$. These results confirm the findings of the two-way ANOVA and demonstrate that NP078585 blocks yohimbine-induced reinstatement of ethanol seeking.

A possible caveat to these findings is that responding on the previously inactive lever was reduced by the combination of NP078585 and yohimbine (Fig. 4B). A two-way repeatedmeasures ANOVA with factors for pretreatment and yohimbine showed a significant effect of pretreatment $(p=0.038)$ but not yohimbine ( $p=0.434)$ with a significant interaction between the two factors $(p=0.044)$. Post hoc Bonferroni tests revealed significant effects of yohimbine within NP078585 treatment and of pretreatment (vehicle vs NP078585) within yohimbine treatment $(p<0.05)$. To further investigate the effects of yohimbine and NP078585 on locomotor activity, we performed a separate experiment where locomotor activity was analyzed in a habituated environment. Yohimbine stimulated locomotor activity relative to vehicle treatment alone, a phenomenon that has been described previously (Mason et al., 1998; Schroeder et al., 2003). NP078585 prevented this stimulation, but did not reduce locomotor activity relative to vehicle and had no effect by itself (Fig. $4 C)$. Analysis by one-way ANOVA revealed a significant difference $\left(F_{(3,33)}=8.207 ; p<0.05\right)$ with a post hoc Bonferroni test demonstrating a significant difference between the vehicle + yohimbine group versus all other groups $(p<0.05)$.

\section{Ethanol clearance}

To investigate whether NP078585 alters ethanol metabolism, we measured blood alcohol levels 30, 90 and 180 min after injection of $4 \mathrm{~g} / \mathrm{kg}$ ethanol in wild-type F1 C57BL/6J × 129/S4 hybrid mice that had been pretreated with $25 \mathrm{mg} / \mathrm{kg}$ NP078585 or vehicle. These time points were chosen based on their relevance to the acute sensitivity experiments described in Figure 1. It is our experience that peak blood ethanol concentrations are achieved at 30 min using tail blood sampling in this strain of mice (Newton et al., 2004). Clearance of ethanol from the blood did not differ between vehicle and NP078585 treated mice (Fig. 5). A two-way ANOVA with a between-subjects factor for pretreatment and a within-subjects factor for time showed no effect of pretreatment $\left(F_{(1,23)}=1.272 ; p=0.279\right)$ but a significant effect of time $\left(F_{(2,23)}\right.$ $=53.562 ; p<0.001)$ with no significant interaction between the two factors $\left(F_{(2,23)}=0.197 ; p=0.822\right)$. Additionally, we have previously shown that mice lacking $\mathrm{N}$-type calcium channels show no differences in the clearance of ethanol when compared with their wild-type littermates (Newton et al., 2004). 


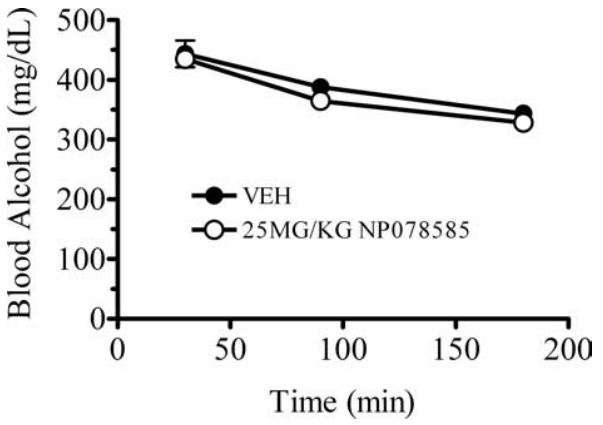

Figure 5. NP078585 treatment does not alter the clearance of ethanol from the blood. Mice were treated with vehicle or NP078585 $(25 \mathrm{mg} / \mathrm{kg}) 30 \mathrm{~min}$ before ethanol $(4 \mathrm{~g} / \mathrm{kg})$. Blood alcohol concentration was assayed at the times indicated. There was no difference in clearance between vehicle and NP078585 treated mice ( $p>0.05$ by two-way repeated-measures ANOVA).

\section{Discussion}

The purpose of this study was to test our hypothesis that N-type calcium channels are a potential drug target for the treatment of alcoholism. We hypothesized that an N-type calcium channel antagonist would attenuate the acute intoxicating effects of ethanol and reduce alcohol reward, reinforcement, and reinstatement. We observed that the mixed $\mathrm{N}$ - and T-type calcium channel antagonist NP078585 reduced the acute effects of ethanol and abolished the expression of ethanol conditioned place preference by mice. In rats, NP078585 abolished stress-induced reinstatement of ethanol-seeking and had a delayed effect on operant self-administration of ethanol; responding was not affected immediately after NP078585 treatment, but it was reduced the day after. These findings indicate that NP078585 reduces ethanol intoxication, reward, self-administration, and reinstatement, supporting our hypothesis that $\mathrm{N}$-type calcium channels contribute to these behaviors.

Treatment with NP078585 alone was not sedating to rats or mice, and no obvious behavioral side effects were observed. NP078585 is the parent compound of a class of N-type calcium channel inhibitors that have been investigated in human clinical trials for the treatment of chronic pain, where they were well tolerated (The Healthcare Marketing and Sales Network, March 20, 2006). Additional N-type calcium channel inhibitors are being developed for clinical use (Schroeder et al., 2006). These studies, together with the data presented here, suggest that novel $\mathrm{N}$-type calcium channel inhibitors be further investigated as candidate drugs for the treatment of alcoholism.

Prior behavioral experiments using snail toxins to inhibit calcium channels are difficult to interpret because many of these toxins cause motor impairment and toxicity in rodents (Olivera et al., 1994). Despite this, a previous study investigating the role of N-type calcium channels in hypnotic responses to ethanol showed that intraventricular administration of $\omega$-conotoxin GVIA prolonged the ethanol-induced loss of the righting reflex when given $4 \mathrm{~h}$ before ethanol in food-deprived rats (Brown et al., 1993). The discrepancy between the data obtained in that study and our data presented here may be related to the fact that $\omega$-conotoxin GVIA exhibits some off-target activities, including inhibition of L-type calcium channels (McCleskey et al., 1987). Brown et al. also observed an increase in both spontaneous and evoked tremor after $\omega$-conotoxin GVIA treatment, and these motor side effects may have impaired the righting reflex. The effects of $\omega$-conotoxin GVIA on other ethanol-related behaviors has not been investigated, perhaps because of the side effects described above. Although NP078585 also inhibits T-type $\mathrm{Ca}^{2+}$ channels in vitro, we did not observe any effects of NP078585 in mice lacking $\mathrm{N}$-type calcium channels that had been given a hypnotic dose of ethanol. These results indicate that in the loss of righting-reflex paradigm, NP078585 is largely acting via N-type channel blockade, although we cannot rule out the possibility that NP078585 is acting through T-type calcium channels in other paradigms.

We have previously shown, in experiments with the PC12 cell line, that ethanol inhibits the function of $\mathrm{N}$-type calcium channels (Solem et al., 1997). Thus pretreatment with an N-type calcium channel antagonist might be expected to potentiate, rather than antagonize, the acute effects of ethanol. There are a number of potential explanations for this apparent confound. The cell culture observations may not be relevant to the in vivo effects of ethanol, where a number of other ion channels and second messengers are important (Narahashi et al., 2001; Newton and Messing, 2006). Also the 1997 study was conducted using $\omega$-conotoxin GVIA and is thus subject to the same caveats as described above. Finally, as mentioned above NP078585 may itself be acting through targets other than N-type calcium channels in some paradigms.

Ethanol has repeatedly been demonstrated to increase neurotransmitter release at GABAergic synapses (Siggins et al., 2005). Given the role of T-type calcium channels in mediating oscillatory and rebound burst behaviors, together with the presynaptic location of N-type channels and their demonstrated role in regulating GABA release at a number of different synapses (Tredway et al., 1999; Poncer et al., 2000; Momiyama and Koga, 2001), it is possible that the combined effects of blocking $\mathrm{N}$ - and T-type type channels with NP078585 may be to inhibit ethanol-induced increases in GABA release and so reduce the behavioral effects of ethanol. This would also require that the inhibitor block only the increase in GABA release seen after ethanol treatment without affecting baseline release. Such a circumstance has been demonstrated in chick brain slices, where $\omega$-conotoxin GVIA pretreatment blocks nicotinic acetylcholine receptor-mediated enhancement of GABA release without affecting baseline release (Tredway et al., 1999).

We observed that NP078585 abolished the expression of an ethanol conditioned place preference in mice, a property it shares with naltrexone (Middaugh and Bandy, 2000), which is the most effective approved medication for the treatment of alcohol use disorders (Anton et al., 2006). Because N-type calcium channels have been postulated to play a role in learning and memory (Jeon et al., 2006), we determined whether NP078585 caused a general impairment of the recall of a conditioned stimulus by assessing the effect of NP078585 on the expression of a lithium chloride conditioned place aversion. $\mathrm{LiCl}$ produced a conditioned response similar in magnitude to that obtained with ethanol. NP078585 did not affect the expression of this conditioned place aversion, confirming that NP078585 does not produce a general deficit in the recall of conditioned stimuli.

Our ethanol place preference data initially appear to be contrasted by the data from our operant self-administration experiments with Long-Evans rats, where NP078585 did not alter operant responding on the day it was given; these operant data would suggest that NP078585 does not diminish motivation to experience the effects of ethanol. There are a number of potential explanations for the apparent discrepancy between these two results. They were derived from different paradigms and different species, involving passive versus voluntary exposure to different ethanol concentrations over very different durations. The debate about similarities and differences between place preference and 
operant self-administration experiments is a lengthy and ongoing one (Sanchis-Segura and Spanagel, 2006; Tzschentke, 2007). Perhaps the most attractive explanation is the difference in the amounts of alcohol involved in the two experiments. In the conditioned place preference assay, animals are motivated by the subjective effects of an experimenter-administered $2 \mathrm{~g} / \mathrm{kg}$ ethanol injection which should result in blood alcohol concentrations of $\sim 100 \mathrm{mg} \%$ in DBA/2 mice (Chester and Cunningham, 1999), which is a dose sufficient to cause significant intoxication. In the operant self-administration experiment, Long-Evans rats were trained to voluntarily self-administer $\sim 0.47 \mathrm{~g} / \mathrm{kg}$ ethanol. Although we did not measure blood alcohol concentrations in the current study, published reports indicate that Long-Evans rats self-administering this amount of alcohol attain a blood alcohol concentrations of 20-25 mg\%, approximately the level encountered by human social drinkers (Czachowski et al., 1999; Gauvin, 1999; Roberts et al., 1999). These data suggest that the motivation to experience a lower dose of ethanol is not affected by NP078585, whereas the motivation to experience a higher dose is attenuated by this drug.

Although NP078585 did not decrease operant responding on the day it was given, it did decrease responding on the following day. Thus, the rewarding effects of a low dose of ethanol may be diminished or its aversive effects enhanced when consumed under the influence of NP078585. A similar pattern is seen in studies where human alcoholics are allowed to continue drinking while taking naltrexone; alcohol intake declines gradually through a process that is thought to be similar to extinction (Sinclair, 2001). Studies involving repeated dosing of NP078585 during selfadministration will address whether NP078585 has similar effects. In animal studies, a similar pattern has been observed for the effect of naloxone on the reinforcing properties of heroin in a runway assay (McFarland and Ettenberg, 1998); naloxone had no effect on the day it was administered, but responding was reduced $24 \mathrm{~h}$ later, suggesting that naloxone does not alter motivation to seek heroin, but rather it diminishes the reinforcing effects of heroin. Similar changes are seen in negative contrast paradigms where animals are trained to stably respond for a fixed concentration of sucrose (e.g., 32\%). Devaluing the reinforcer by reducing the concentration of sucrose results in a decrease in consumption (Grigson, 2000). All of these hypotheses are the subject of ongoing studies.

Regardless of the differences, our observation that NP078585 reduces responding in two very different rodent models of ethanol reward and reinforcement (place preference and selfadministration) suggests that N-type calcium channel antagonists may be useful for reducing alcohol consumption in human subjects and underscores the need to use multiple paradigms when developing medications to treat alcoholism (Egli, 2005). In the current study, our paradigm and species selection was designed to most effectively test whether an N-type calcium channel antagonist may be useful as a treatment for alcoholism. This resulted in the use of multiple strains and species which may cause problems for mechanistic interpretations as evidenced by the potentially confounding data obtained in our place preference and self-administration paradigms. We were unable to use a single species throughout the study. We wished to use mice for the simple reason that we were able to test NP078585 in mice lacking $\mathrm{N}$-type calcium channels. Although mice are able to learn the operant ethanol self-administration procedure, it is our experience that more consistent data are obtained from the use of Long-Evans rats. Also, stress-induced reinstatement of operant ethanol seeking by mice does not appear to have been established as a model system, although context and cue-induced reinstatement has been demonstrated (Tsiang and Janak, 2006) as well as stressinduced increases in alcohol preference in a nonoperant paradigm (Racz et al., 2003).

Stress is a significant precipitant of relapse in otherwise abstinent alcoholics (Brown et al., 1995). However, the development of medications to specifically treat stress-induced relapse is problematic because many traditional anxiety medications, such as benzodiazepines, have sedative effects that are additive with those of ethanol. Naltrexone does not attenuate stress-induced reinstatement in rodents (Lê et al., 1999). Our finding that NP078585 completely blocked reinstatement induced by yohimbine suggests that calcium channel antagonists, unlike currently available drugs used to treat alcohol use disorders, may reduce stressinduced relapse. It is interesting to note that yohimbine also stimulated locomotor activity and that this stimulation was also blocked by NP078585. Inactive lever presses were not stimulated by yohimbine treatment so it seems unlikely that the reinstatement of active lever pressing produced by yohimbine was a general effect on locomotor activity. However, we cannot completely rule out the possibility that yohimbine-stimulated increases in locomotor activity contribute to increased responding on the previously active lever and thus the ability of NP078585 to block this locomotor increase may contribute to its ability to block reinstatement of active lever pressing.

In summary, our results demonstrate that the $\mathrm{N}$ - and T-type calcium channel antagonist NP078585 attenuates or abolishes the acute effects of ethanol over a wide range of ethanol doses $(2-4 \mathrm{~g} / \mathrm{kg})$. NP078585 also reduces the conditioned motivational effects of an intoxicating dose of ethanol, decreases the reinforcing effects of a low dose of ethanol, and blocks stress-induced reinstatement of ethanol seeking. These data offer the attractive possibility that human alcoholics treated with $\mathrm{N}$-type or mixed $\mathrm{N}$ - and T-type calcium channel inhibitors may become less motivated to experience the effects of ethanol, and those effects might be reduced should they drink while under treatment.

\section{References}

Anton RF, O’Malley SS, Ciraulo DA, Cisler RA, Couper D, Donovan DM, Gastfriend DR, Hosking JD, Johnson BA, LoCastro JS, Longabaugh R, Mason BJ, Mattson ME, Miller WR, Pettinati HM, Randall CL, Swift R, Weiss RD, Williams LD, Zweben A (2006) Combined pharmacotherapies and behavioral interventions for alcohol dependence: the COMBINE study: a randomized controlled trial. JAMA 295:2003-2017.

Brown LM, Sims JS, Randall P, Wilcox R, Leslie SW (1993) Omega-conotoxin increases sleep time following ethanol injection. Alcohol 10:159-162.

Brown SA, Vik PW, Patterson TL, Grant I, Schuckit MA (1995) Stress, vulnerability and adult alcohol relapse. J Stud Alcohol 56:538-545.

Burattini C, Gill TM, Aicardi G, Janak PH (2006) The ethanol selfadministration context as a reinstatement cue: acute effects of naltrexone. Neuroscience 139:877-887.

Chester JA, Cunningham CL (1999) GABA(A) receptors modulate ethanolinduced conditioned place preference and taste aversion in mice. Psychopharmacology (Berl) 144:363-372.

Cunningham CL, Henderson CM, Bormann NM (1998) Extinction of ethanol-induced conditioned place preference and conditioned place aversion: effects of naloxone. Psychopharmacology (Berl) 139:62-70.

Czachowski CL, Samson HH, Denning CE (1999) Blood ethanol concentrations in rats drinking sucrose/ethanol solutions. Alcohol Clin Exp Res 23:1331-1335.

Dawson-Saunders B, Trapp RG (1994) Basic and clinical biostatistics, Ed 1. East Norwalk, CT: Appleton and Lange.

Dubel SJ, Starr TV, Hell J, Ahlijanian MK, Enyeart JJ, Catterall WA, Snutch TP (1992) Molecular cloning of the $\alpha$-1 subunit of an $\omega$-conotoxinsensitive calcium channel. Proc Natl Acad Sci U S A 89:5058-5062.

Dunlap K, Luebke JI, Turner TJ (1995) Exocytotic $\mathrm{Ca}^{2+}$ channels in mammalian central neurons. Trends Neurosci 18:89-98. 
Egli M (2005) Can experimental paradigms and animal models be used to discover clinically effective medications for alcoholism? Addict Biol 10:309-319.

Finney JW, Hahn AC, Moos RH (1996) The effectiveness of inpatient and outpatient treatment for alcohol abuse: the need to focus on mediators and moderators of setting effects. Addiction 91:1773-1796; discussion 1803-1820.

Gass JT, Olive MF (2007) Reinstatement of ethanol-seeking behavior following intravenous self-administration in wistar rats. Alcohol Clin Exp Res 31:1441-1445.

Gauvin DV (1999) Blood alcohol concentrations in rats drinking or intubated with ethanol. Alcohol Clin Exp Res 23:1945-1947.

Ghosh A, Greenberg ME (1995) Calcium signaling in neurons: Molecular mechanisms and cellular consequences. Science 268:239-247.

Grigson PS (2000) Drugs of abuse and reward comparison: a brief review. Appetite 35:89-91.

Huguenard JR (1996) Low-threshold calcium currents in central nervous system neurons. Annu Rev Physiol 58:329-348.

Jeon D, Kim C, Yang YM, Rhim H, Yim E, Oh U, Shin HS (2006) Impaired long-term memory and long-term potentiation in N-type Ca channeldeficient mice. Genes Brain Behav 6:375-388.

Kenna GA, McGeary JE, Swift RM (2004a) Pharmacotherapy, pharmacogenomics, and the future of alcohol dependence treatment, Part 2. Am J Health Syst Pharm 61:2380-2388.

Kenna GA, McGeary JE, Swift RM (2004b) Pharmacotherapy, pharmacogenomics, and the future of alcohol dependence treatment, part 1. Am J Health Syst Pharm 61:2272-2279.

Lê AD, Poulos CX, Harding S, Watchus J, Juzytsch W, Shaham Y (1999) Effects of naltrexone and fluoxetine on alcohol self-administration and reinstatement of alcohol seeking induced by priming injections of alcohol and exposure to stress. Neuropsychopharmacology 21:435-444.

Le AD, Harding S, Juzytsch W, Funk D, Shaham Y (2005) Role of alpha-2 adrenoceptors in stress-induced reinstatement of alcohol seeking and alcohol self-administration in rats. Psychopharmacology (Berl) 179:366-373.

Lessov CN, Palmer AA, Quick EA, Phillips TJ (2001) Voluntary ethanol drinking in $\mathrm{C} 57 \mathrm{BL} / 6 \mathrm{~J}$ and DBA/2J mice before and after sensitization to the locomotor stimulant effects of ethanol. Psychopharmacology (Berl) 155:91-99.

Marinelli PW, Funk D, Juzytsch W, Harding S, Rice KC, Shaham Y, Le AD (2007) The CRF(1) receptor antagonist antalarmin attenuates yohimbine-induced increases in operant alcohol self-administration and reinstatement of alcohol seeking in rats. Psychopharmacology (Berl) 195:345-355.

Mason K, Heal DJ, Stanford SC (1998) The anxiogenic agents, yohimbine and FG 7142, disrupt the noradrenergic response to novelty. Pharmacol Biochem Behav 60:321-327.

McCleskey EW, Fox AP, Feldman DH, Cruz LJ, Olivera BM, Tsien RW, Yoshikami D (1987) Omega-conotoxin: direct and persistent blockade of specific types of calcium channels in neurons but not muscle. Proc Natl Acad Sci U S A 84:4327-4331.

McFarland K, Ettenberg A (1998) Naloxone blocks reinforcement but not motivation in an operant runway model of heroin-seeking behavior. Exp Clin Psychopharmacol 6:353-359.

McMahon T, Andersen R, Metten P, Crabbe JC, Messing RO (2000) Protein kinase $\mathrm{C}$ epsilon mediates up-regulation of $\mathrm{N}$-type calcium channels by ethanol. Mol Pharm 57:53-58.

Middaugh LD, Bandy AL (2000) Naltrexone effects on ethanol consumption and response to ethanol conditioned cues in C57BL/6 mice. Psychopharmacology (Berl) 151:321-327.

Momiyama T, Koga E (2001) Dopamine D(2)-like receptors selectively block $\mathrm{N}$-type $\mathrm{Ca}(2+)$ channels to reduce GABA release onto rat striatal cholinergic interneurones. J Physiol 533:479-492.

Mu J, Carden WB, Kurukulasuriya NC, Alexander GM, Godwin DW (2003) Ethanol influences on native T-type calcium current in thalamic sleep circuitry. J Pharmacol Exp Ther 307:197-204.

Narahashi T, Kuriyama K, Illes P, Wirkner K, Fischer W, Mühlberg K, Scheibler P, Allgaier C, Minami K, Lovinger D, Lallemand F, Ward RJ, DeWitte P, Itatsu T, Takei Y, Oide H, Hirose M, Wang XE, Watanabe S, Tateyama M, et al. (2001) Neuroreceptors and ion channels as targets of alcohol. Alcohol Clin Exp Res 25:182S-188S.

Newton PM, Messing RO (2006) Intracellular signaling pathways that regulate behavioral responses to ethanol. Pharmacol Ther 109:227-237.

Newton PM, Messing RO (2007) Increased sensitivity to the aversive effects of ethanol in PKCepsilon null mice revealed by place conditioning. Behav Neurosci 121:439-442.

Newton PM, Orr CJ, Wallace MJ, Kim C, Shin HS, Messing RO (2004) Deletion of N-type calcium channels alters ethanol reward and reduces ethanol consumption in mice. J Neurosci 24:9862-9869.

Newton PM, Tully K, McMahon T, Connolly J, Dadgar J, Treistman SN, Messing RO (2005) Chronic ethanol exposure induces an N-type calcium channel splice variant with altered channel kinetics. FEBS Lett 579:671-676.

Newton PM, Kim JA, McGeehan AJ, Paredes JP, Chu K, Wallace MJ, Roberts AJ, Hodge CW, Messing RO (2007) Increased response to morphine in mice lacking protein kinase C epsilon. Genes Brain Behav 6:329-338.

Olivera BM, Miljanich GP, Ramachandran J, Adams ME (1994) Calcium channel diversity and neurotransmitter release: the $\omega$-conotoxins and $\omega$-agatoxins. Annu Rev Biochem 63:823-867.

Poncer JC, McKinney RA, Gahwiler BH, Thompson SM (2000) Differential control of GABA release at synapses from distinct interneurons in rat hippocampus. J Physiol 528:123-130.

Racz I, Bilkei-Gorzo A, Toth ZE, Michel K, Palkovits M, Zimmer A (2003) A critical role for the cannabinoid CB1 receptors in alcohol dependence and stress-stimulated ethanol drinking. J Neurosci 23:2453-2458.

Risinger FO, Cunningham CL (2000) DBA/2J mice develop stronger lithium chloride-induced conditioned taste and place aversions than C57BL/6J mice. Pharmacol Biochem Behav 67:17-24.

Roberts AJ, Heyser CJ, Koob GF (1999) Operant self-administration of sweetened versus unsweetened ethanol: effects on blood alcohol levels. Alcohol Clin Exp Res 23:1151-1157.

Sanchis-Segura C, Spanagel R (2006) Behavioural assessment of drug reinforcement and addictive features in rodents: an overview. Addict Biol 11:2-38.

Schroeder BE, Schiltz CA, Kelley AE (2003) Neural activation profile elicited by cues associated with the anxiogenic drug yohimbine differs from that observed for reward-paired cues. Neuropsychopharmacology 28:14-21.

Schroeder CI, Doering CJ, Zamponi GW, Lewis RJ (2006) N-type calcium channel blockers: novel therapeutics for the treatment of pain. Med Chem 2:535-543.

Siggins GR, Roberto M, Nie Z (2005) The tipsy terminal: presynaptic effects of ethanol. Pharmacol Ther 107:80-98.

Sinclair JD (2001) Evidence about the use of naltrexone and for different ways of using it in the treatment of alcoholism. Alcohol Alcohol 36:2-10.

Snutch T, Feng Z, Doering C (2001) A new class of N-type calcium channel blocker efficacious in animal models of chronic pain. Soc Neurosci Abstr 27:465.1.

Snutch T, Feng Z, Doering C, Cayabyab F, Janke D, Parker D, Belardetti F, Morimoto B, Vanderah B, Zamponi G, Porreca F (2003) Novel N-type calcium channel blockers efficacious in animal models of chronic pain. Paper presented at 226th ACS National Meeting, New York, NY, September.

Snutch TP (2005) Targeting chronic and neuropathic pain: the N-type calcium channel comes of age. NeuroRx 2:662-670.

Solem M, McMahon T, Messing RO (1997) Protein kinase A regulates inhibition of N- and P/Q-type calcium channels by ethanol in PC12 cells. J Pharmacol Exp Ther 282:1487-1495.

The Healthcare Marketing and Sales Network (2006) News Release, March 20. Retrieved October 24, 2008. http://salesandmarketingnetwork.com/ news_release.php?ID=2010474.

Tredway TL, Guo JZ, Chiappinelli VA (1999) N-type voltage-dependent calcium channels mediate the nicotinic enhancement of GABA release in chick brain. J Neurophysiol 81:447-454.

Tsiang MT, Janak PH (2006) Alcohol seeking in C57BL/6 mice induced by conditioned cues and contexts in the extinction-reinstatement model. Alcohol 38:81-88.

Tzschentke TM (2007) Measuring reward with the conditioned place preference (CPP) paradigm: update of the last decade. Addict Biol 12:227-462.

Walter HJ, Messing RO (1999) Regulation of neuronal voltage-gated calcium channels by ethanol. Neurochem Int 35:95-101.

Xiao W, Naso L, Bennett GJ (2008) Experimental studies of potential analgesics for the treatment of chemotherapy-evoked painful peripheral neuropathies. Pain Med 9:505-517.

Zar JH (1984) Biostatistical analysis, Ed 2. Englewood Cliffs, NJ: Prentice-Hall. 